\title{
RANCANG BANGUN KONDENSOR PADA DESTILATOR BIOETANOL KAPASITAS 5 LITER/JAM DENGAN SKALA UMKM
}

\author{
Budi Rubianto \\ Fakultas Teknik, Program Studi Teknik Mesin \\ Universitas Muria Kudus \\ Email:201454102@std.umk.ac.id \\ Rochmad Winarso \\ Fakultas Teknik, Program Studi Teknik Mesin \\ Universitas Muria Kudus \\ Email: rochmad.winarso@umk.ac.id \\ Rianto Wibowo \\ Fakultas Teknik, Program Studi Teknik Mesin \\ Universitas Muria Kudus \\ Email: rianto.wibowo@,umk.ac.id
}

\begin{abstract}
ABSTRAK
Penggunaan bahan bakar minyak khususnya bahan bakar fosil disamping ketersediaannya semakin terbatas juga dapat merusak lingkungan yaitu menimbulkan polusi udara. Maka dioperlukan produksi energi alternatif yang ramah lingkungan sebagai energi terbarukan pengganti bahan bakar fosil yaitu bioethanol. Dalam pelaksanaannya diperlukan alat sebagai proses destilasi yaitu destilator berpendingin kondensor untuk menghasilkan bioethanol. Kondensor berfungsi untuk mendinginkan uap ethanol pada siklus destilasi dari alat destilator bioethanol. Metode yang digunakan meliputi studi literatur, analisa kebutuhan teknis, proses perancangan, proses simulasi, gambar kerja, proses pembuatan, dan proses pengujian kondensor. Hasil yang diperoleh meliputi dimensi kondensor dengan tinggi total $600 \mathrm{~mm}$ dengan diameter $200 \mathrm{~mm}$. menghasilkan ethanol dengan kapasitas 2,35 liter/jam dengan kemurnian $91 \%$.
\end{abstract}

Kata kunci: bioethanol,destilator, kemurnian, kondensor.

\section{ABSTRACT}

The use of fuel oil, especially fossil fuels, in addition to its increasingly limited availability can also damage the environment, which causes air pollution. Then the production of alternative energy that is environmentally friendly as a renewable energy substitute for fossil fuels is bioethanol. In its implementation, a device is needed as a distillation process, which is a condenser-cooled distillator to produce bioethanol. The condenser functions to cool ethanol vapor in the distillation cycle from the bioethanol destilator. The method used includes literature studies, technical requirements analysis, design process, simulation process, work drawings, manufacturing processes, and condenser testing processes. The results obtained include the dimensions of the condenser with a total height of $600 \mathrm{~mm}$ with a diameter of $200 \mathrm{~mm}$. produces ethanol with a capacity of 2.35 liters / hour with a purity of $91 \%$.

Keywords: Bioethanol, destilator, purity, condenser.

\section{PENDAHULUAN}

Indonesia termasuk dalam organisasi penghasil minyak dunia, yaitu pada tahun 1989 menempati urutan 10 besar sebagai penghasil minyak bumi. Tetapi seiring dengan perkembangan jaman dan teknologi kebutuhan akan minyak setiap tahun akan terus mengalami peningkatan, 
maka perlu adanya penghematan dalam penggunaan bahan bakar minyak tersebut. Penggunaan bahan bakar minyak khususnya bahan bakar fosil disamping ketersediaannya semakin terbatas juga dapat merusak lingkungan yaitu menimbulkan polusi udara [1]. Sehingga diperlukan energi alternatif sebagai proses pemenuhan energi yang dibutuhkan yaitu bioethanol.

Bioetanol merupakan suatu bentuk energy alternatif, karena dapat mengurangi ketergantungan terhadap Bahan Bakar Minyak (pengganti premium dan pertamax), sehingga pemakaiannya akan menghemat devisa dan sekaligus sebagai pemasok energi nasional. Bioetanol dapat diperoleh dari fermentasi bahan - bahan yang mengandung amilum, sukrosa, glukosa, maupun fruktosa, yang dihasilkan dari tetes tebu, singkong, jagung, sorghum maupun aren, sehingga bioethanol merupakan energi yang dapat diperbaharui. Bahan baku pembuatan bioetanol dibagi menjadi tiga kelompok yaitu bahan bersukrosa, bahan berpati, dan bahan berselulosa. Penggunaan bahan-bahan tersebut sebagai bahan baku bioetanol sudah banyak dilakukan. Diantaranya sari buah-buahan, ubi kayu, ubi jalar dan lainlain [2].

Dengan bahan baku bioethanol tersebut perlu adaya alat untuk memprosesnya, alat tersebut adalah destilator bioethanol dimana pada destilator tersebut diperlukan alat pendingin, yaitu kondensor. Kondensor merupakan komponen pendingin yang sangat penting yang berfungsi untuk memaksimalkan efisiensi pada mesin pendingin. Pada kondensor ini terjadi pelepasan kalor secara kondensasi dan kalor sensibel. Pada umumnya menggunakan kondensor tipe permukaan (surface condenser), tipe kondensor ini merupakan jenis shell-tube yang mana air pendingin disirkulasikan melalui tube[3].

Untuk memperoleh performan yang sebaik-baiknya maka alat penukar kalor harus dirancang dengan cara yang seksama dan seoptimal mungkin. Oleh karena itu penguasaan metode perancangan sebuah alat penukar kalor menjadi sangat penting karena akan memberikan kontribusi yang sangat besar kepada upaya peningkatan performance instalasi industri, yang berarti juga kepada upaya penghematan energi terutama di sektor industri[4].

Pada penelitian sebelumnya telah di hasilkan tingkat kadar etanol mencapai $92 \%$ dengan waktu fermentasi selama 7 hari sedangkan bahan uji menggunakan ketela pohon[5].

Dari penelitian ini diharapkan mampu melakukan perancangan sebuah alat penukar kalor (APK) sesuai dengan standar yang berlaku sehingga dapat dihasilkan alat penukar kalor (APK) yang memiliki efektifitas yang tinggi[6].

Setelah melakukan pengamatan pemodelan kondensor terdapat beberapa kondensor tidak melalui proses pengujian terlebih dahulu sehingga proses kondensasi tidak dapat menghasilkan etanol yang diinginkan, dengan adanya proses perancangan kondensor pada destilator bioethanol dan melalui pengujian maka mendapatkan kondensasi yang sempurna dengan hasil etanol sesuai yang diinginkan, sehingga etanol yang diinginkan dapat tercapai sesuai dengan standar yang telah di tentukan sebelumnya.

\section{METODOLOGI PENELITIAN}

Setelah melakukan perancangan kondensor pada destilator bioetanol kapasitas 5 liter/jam dengan skala UMKM maka di perlukan diagram alir. Diagram alir dapat dilihat pada gambar 1 berikut ini: 


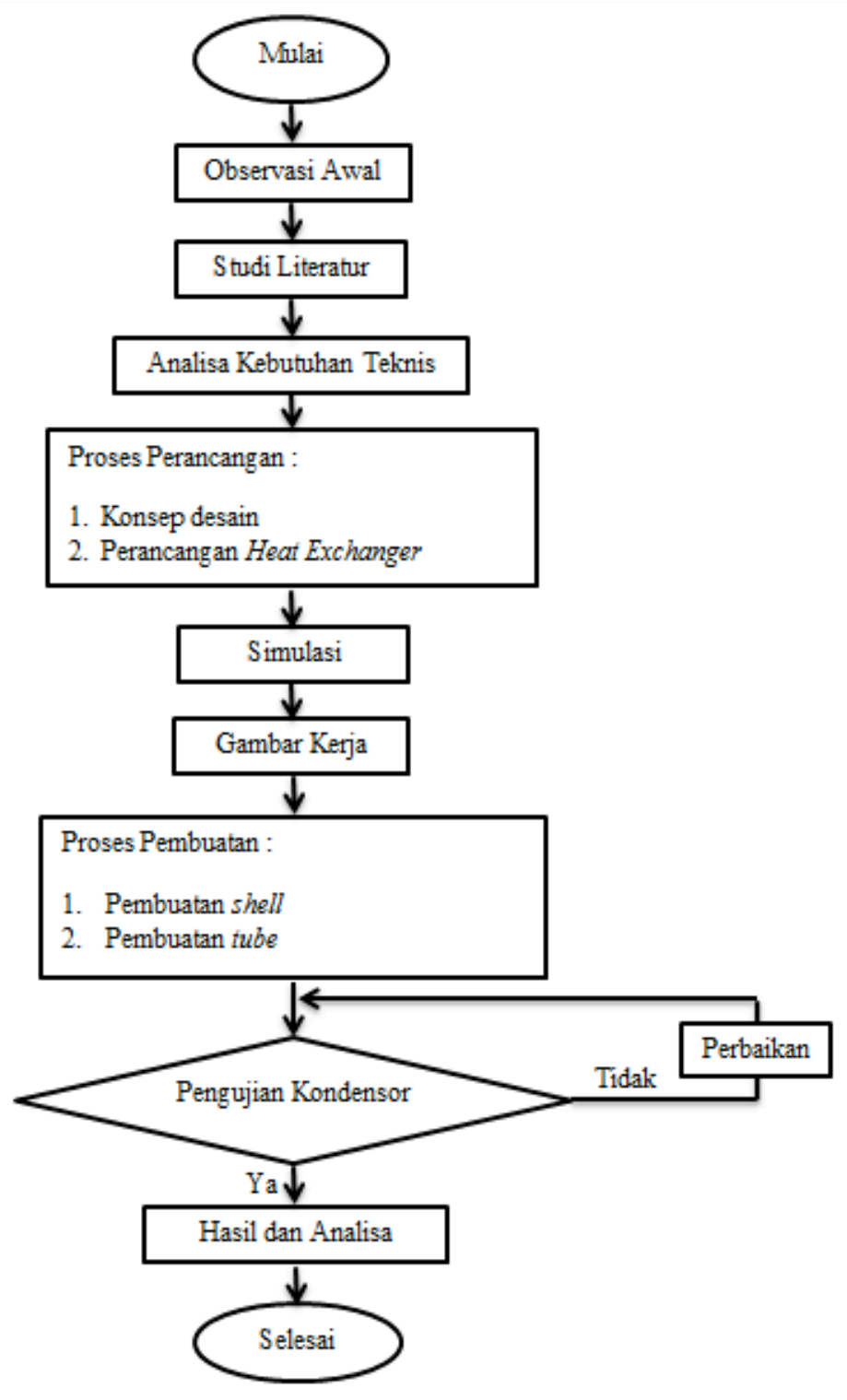

\section{Gambar 1 Diagram Alir Penelitian Kondensor}

Tahap pertama dilakukan proses observasi lapangan pada komponen kondensor dari destilator bioethanol, selanjutnya dilakukan studi literatur pada artiket - artikel terkait, proses perancangan pada kondensor kemudian setelah melakukan perancangan di lanjutkan ke proses pembuatan kondensor. Setelah melakukan proses perancangan dan pembuatan kemudian melakukan proses pengujian untuk mengetahui layak atau tidaknya kondensor tersebut digunakan.

Dari beberapa proses pemilihan desain kondensor type helical tube adalah desain yang tepat karena konsep tersebut penampangnya lebih luas. dapat dilihat pada gambar 2 berikut ini : 


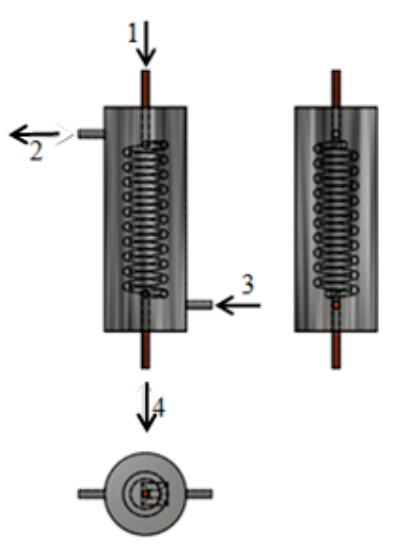

\section{Gambar 2. Kondensor}

Keterangan :

1. Uap masuk.

2. Air pendingin keluar.

3. Air pendingin masuk.

4. Kondensat / sudah menjadi etanol.

Prinsip kerja kondensor :

1. Uap dari menara refluks masuk ke pipa tembaga (tube).

2. Air pendingin dari tangki di alirkan dengan menggunakan pompa menuju ke tabung kondensor (shell).

3. Air akan bekerja untuk mendinginkan uap dengan cara sirkulasi.

4. Setelah melewati proses kondensasi uap tersebut akan menjadi etanol.

\section{HASIL DAN PEMBAHASAN}

\subsection{Kondensor}

Kondensor merupakan alat penukar kalor yang berfungsi sebagai tahap akhir destilasi dengan cara mengubah uap panas menjadi etanolmelalui proses kondensat atau pengembunan.[7]

Perancangan kondensor pada destilator bioethanol adalah berupa proses perencanaan pada shell dan tube yang akan digunakan untuk proses heat transfer. Adanya proses perhitungan ini bertujuan untuk memaksimal etanol yang akan dihasilkan pada saat pengujian mesin destilator bioethanol.

Perhitungan perancangan kondensor merupakan perhitungan untuk mencari nilai LMTD, faktor koreksi, reynold numer, nuzlt number, koefisien konveksi perpindahan panas, koefisien perpindahan panas total, kalor, luas permukaan, panjang pipa, jumah pitch, jarak pitch, berdasarkan pada rumus berikut [8]:

Perhitungan Log Mean Temperature Differential (LMTD) dapat dilihat pada rumus 1:

$\Delta \mathrm{T}_{\mathrm{LMTD}}=\frac{\Delta \mathrm{T}_{1}-\Delta \mathrm{T}_{2}}{\ln \left(\frac{\Delta \mathrm{T}_{1}}{\Delta \mathrm{T}_{2}}\right)}$ 
$\Delta \mathrm{T}_{1}$ merupakan selisih temperatur uap masuk dan air pendingin keluar, $\Delta \mathrm{T}_{2}$ merupakan selisih temperatur uap keluar dan air pendingin masuk. Perhitungan faktor koreksi $(\mathrm{Fc})$ dapat dilihat pada rumus 2:

$$
F c=\frac{\sqrt{\mathrm{R}^{2}+1} \cdot(\mathrm{p}+1)}{\mathrm{R}+1 \cdot \ln \frac{\mathrm{P}}{\mathrm{R}}}
$$

$\mathrm{R}$ merupakan laju rasio, $\mathrm{P}$ merupakan efektifitas temperatur fluida dingin. Perhitungan reynolds number $(\mathrm{Re})$ dapat dilihat pada rumus 3 :

$\operatorname{Re}=\frac{\rho \cdot u \cdot d i n}{\mu}$

$\rho$ merupakan massa jenis gas, u merupakan kecepatan laju aliran, $\mu$ merupakan koefisien gesek, $\mathrm{d}_{\text {in }}$ merupakan diameter dalam. Perhitungan nuzelt number $(\mathrm{Nu})$ dapat dilihat pada rumus 4 :

$$
\mathrm{Nu}=2,8 \cdot \mathrm{De}^{0,2} \cdot \operatorname{Pr} .^{0,28}
$$

De merupakan equifalen, Pr merupakan prandel number. Perhitungan koefisien konveksi perpindahan panas dapat dilihat pada rumus 5:

$$
\mathrm{h}_{\mathrm{i}}=\mathrm{Nu} \cdot \frac{\mathrm{k}}{\mathrm{d}_{\mathrm{in}}}
$$

Nu merupakan Nuzzelt Number, k merupakan konduktifitas termal, $\mathrm{d}_{\text {in }}$ merupakan diameter dalam. Perhitungan koefisien perpindahan panas total (Uo) dapat dilihat pada rumus 6 :

$$
\mathrm{Uo}=\frac{1}{\mathrm{hi}}+\mathrm{R}_{\mathrm{fi}}+\frac{\mathrm{t}}{\mathrm{k}}+\frac{1}{\mathrm{ho}}
$$

h merupakan koefisien konveksi, Rfi merupakan resinstance of fouling factor, t merupakan tebal dinding, k merupakan konduktivitas termal.Perhitungan kalor (Q) dapat dilihat pada rumus 7:

$$
\mathrm{Q}=\mathrm{m}_{\text {uap }} \cdot \mathrm{c}_{\mathrm{p}} \cdot\left(\mathrm{T}_{\mathrm{hi}}-\mathrm{T}_{\mathrm{ho}}\right)
$$

$\mathrm{m}_{\text {uap }}$ merupakan laju aliran uap, $\mathrm{c}_{\mathrm{p}}$ merupakan spesifik heat, $\mathrm{T}_{\mathrm{hi}}$ merupakan uap panas masuk, $\mathrm{T}_{\mathrm{ho}}$ merupakan uap keluar (etanol). Perhitungan luas permukaan pipa (A) dapat dilihat pada rumus 8 :

$$
\mathrm{A}=\frac{\mathrm{Q}}{\text { Uo.F. } \Delta \mathrm{Tm}}
$$

Q merupakan kalor, Uo merupakan koefisien perpindahan panas total, F merupakan faktor koreksi, $\Delta \mathrm{Tm}$ merupakan nilai LMTD yang sudah dihiung dengan faktor koreksi. Perhitungan panjang pipa (L) dapat dilihat pada rumus 9:

$$
\mathrm{L}=\frac{\mathrm{A}}{\pi \cdot \mathrm{d}}
$$


A merupakan permukaan pipa, d merupakan diameter pipa. Perhitungan jumlah pitch (n) dapat dilihat rumus 10:

$\mathrm{n}=\frac{\text { Panjang Tembaga }}{\text { Panjang1 pitch }}$

Jumlah pitch dapat dicari dengan mengetahui panjang tembaga dibagi dengan panjah 1 pitch. Jarak pitch (l) dapat dilihat pada rumus 11:

$l=\frac{\mathrm{a}}{\mathrm{n}}$

a merupakan luas permukaan pipa, n merupakan jumlah pitch.

\subsection{Hasil Perhitungan Kondensor}

Perhitungan dalam perancangan kondensor didasarkan pada beberapa rumus sebagaimana pada rumus 1-11 dengan hasil dapat dilihat pada tabel 1 sebagai berikut:

Tabel 1. Hasil perhitungan kondensor

\begin{tabular}{|c|c|}
\hline Perhitungan & Hasil \\
\hline $\begin{array}{l}\text { Log Mean } \\
\text { (LMTD) }\end{array}$ & $4,8^{0} \mathrm{C}$ \\
\hline Koefisien kalor total (Uo) & $0,00022 \mathrm{~W} /{ }^{0} \mathrm{C}$ \\
\hline Kalor (Q) & $0,0032562 \mathrm{~kW}$ \\
\hline Luas permukaan pipa (A) & $0,426 \mathrm{~m} 2$ \\
\hline Panjang pipa (L) & $6500 \mathrm{~mm}$ \\
\hline Jumlah pitch (n) & 12 \\
\hline Jarak pitch $(l)$ & $50 \mathrm{~mm}$ \\
\hline
\end{tabular}

Berdasarkan proses perhitungan dalam perancangan telah dihasilkan penelitian perancangan kondensor pada destilator bioetanol kapasitas 5 liter/jam dengan skala UMKM, dengan spesifikasi sebagai berikut :

a. Shell

1. Material : Plat stainless steel 304 tebal $2 \mathrm{~mm}$

2. Diameter : $: 200 \mathrm{~mm}$

3. Tinggi : $600 \mathrm{~mm}$

b. Pipa spiral (Tube)

1. Material : Tembaga tebal $1 \mathrm{~mm}$.

2. Diameter : $1 / 2$ inch

3. Panjang : $6500 \mathrm{~mm}$.

\subsection{Proses Simulasi Desain}

Proses simulasi pada perancangan kondensor menggunakan simulasi cfd (Computational Fluida Dynamics) yaitu proses simulasi heat transfer dengan data yang di masukkan berupa temperatur input fluida uap (thi) sebesar $78^{\circ} \mathrm{c}$ dan laju aliran $1,5 \mathrm{~m} / \mathrm{s}$ sedangkan input data fluida air pendingin (tci) sebesar $23^{\circ} \mathrm{c}$ sedangkan debit yang di butuhkan 30 l/menit. Hasilmsimulasi CFD pada kondensor dapat dilihat pada gambar 3 berikut : 


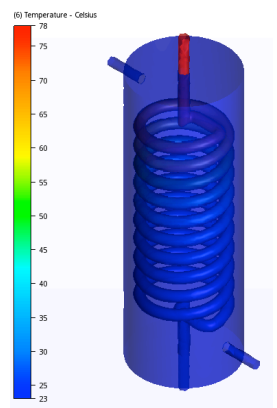

(a)

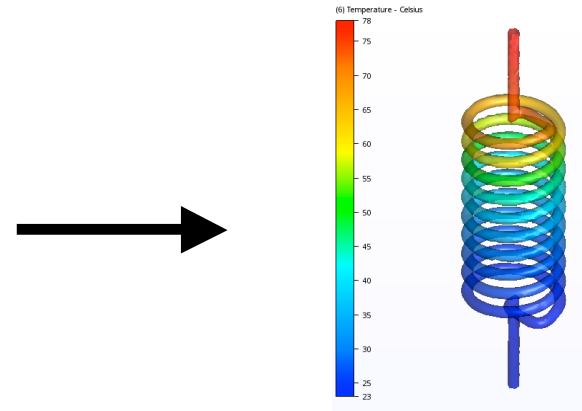

(b)

\section{Gambar 3. Proses Simulasi CFD}

Bedasarkan data simulasi CFD sebagaimana gambar 3 diatas maka di dapatkan hasil data output berupa grafik presentase dari fluida uap (etanol) dan fluida air. Grafik presentase simulasi CFD dapat dilihat pada gambar 4 berikut.

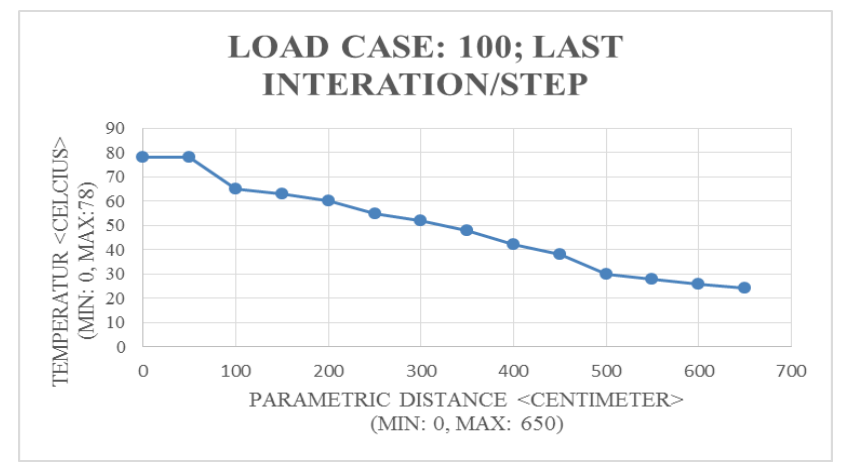

\section{Gambar 4. Grafik Penurunan Suhu Uap}

Data output fluida uap (etanol) berdasarkan grafik yang diperoleh mendapatkan hasil temperatur $24{ }^{\circ} \mathrm{C}$, menandakan terjadi penerunan temperatur kerja pada fluida uap. Sedangkan grafik presentase pada fluida air pendingin dapat dilihat pada gambar 5berikut.

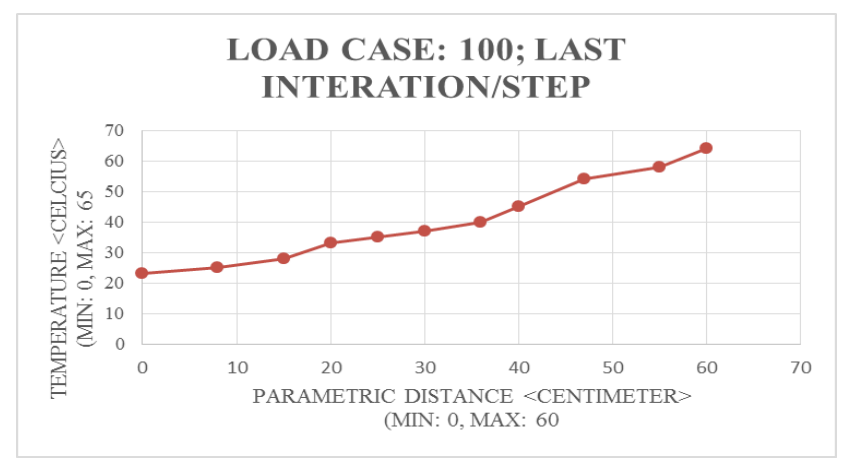

Gambar 5. Grafik Kenaikan Suhu Air Pendingin 
Sedangkan hasil data output grafik presentase fluida air pendingin mencapai temperatur 64 ${ }^{\circ} \mathrm{c}$. Dimana pada fluida pendingin ini mengalami fase kenaikan temperatur kerja.

\section{KESIMPULAN}

Setelah melakukan proses pembuatan kondensor pada destilator bioetanol kapasitas 5 liter/jam dengan skala UMKM, maka di diperoleh hasil kesimpulan sebagai berikut :

1. Telah dirancang dan dibuat kondensor dengan shell berdiameter $200 \mathrm{~mm}$ dan tinggi tabung $600 \mathrm{~mm}$ berbahan stainless steel 304 dan tebal plat $2 \mathrm{~mm}$, sehingga proses sirkulasi air pendingin lebih sempurna.

2. Telah dirancang dan dibuat tube pada kondensor dengan diameter $180 \mathrm{~mm}$ dan tinggi $600 \mathrm{~mm}$ dengan bahan tembaga $1 / 2$ inch dan tebal pipa $1 \mathrm{~mm}$, berbahan pipa tembaga ASTM B208 sehingga proses pendinginan pada uap lebih sempurna .

3. Pada proses pengujian diperoleh temperatur masuk uap $\left(\mathrm{T}_{\mathrm{hi}}\right)$ sebesar $78^{\circ} \mathrm{C}$, sehingga dihasilkan etanol atau temperatur keluar uap $\left(\mathrm{T}_{\text {ho }}\right)$ sebesar $24^{\circ} \mathrm{C}$

4. Telah di hasilkan etanol pada mesin destilator bioetanol dengan hasil 2,35 liter/jam dengan kemurnian $91 \%$.

\section{DAFTAR PUSTAKA}

[1] Sukadana and Tenaya, "Pengaruh Jumlah Tingkat Destilasi Kontinyu terhadap Kualitas dan Kapasitas Produksi Arak Bali sebagai Bahan Bakar Alternatif," Energi dan Manufaktur, vol. 7, pp. 1-2, 2014.

[2] N. K. Sari, "Vapor-Liquid Equilibrium ( Vle ) Water-Ethanol From Bulrush Fermentantion," Tek. Kim., vol. 5, no. 1, p. 5, 2010.

[3] J. Delly, M. Hasbi, and A. Zenius, "Analisa Bioetanol Dari Nira Aren Menggunakan Destilasi Fraksinasi Ganda Sebagai Bahan Bakar,” J. Ilm. Mhs. Tek. mesin, vol. 2, no. 2, pp. 3-4, 2016.

[4] P. M. Ragi, J. Ragi, D. A. N. Waktu, H. S. Jhonprimen, A. Turnip, and M. H. Dahlan, "Pengaruh massa ragi, jenis ragi dan waktu fermentasi pada bioetanol dari biji durian," Tek. Kim., vol. 18, no. 2, p. 4, 2012.

[5] M. Ichsan et al., "Analisa Pengaruh Lama Fermentasi Terhadap Kadar Bioetanol Pada Mesin Destilator Model Reflux," SIMETRIS, vol. 6, no. 2, p. 5, 2015.

[6] S. Ihsan, "Perencanaan dan Analisa Perhitungan Jumlah Tube dan Diameter Shell pada Kondensor Berpendingin Air pada Sistem Refrigerasi NH 3," Teknol. proses Inov. Ind., vol. 2, no. 1, pp. 1-3, 2017.

[7] R. Winarso et al., "Pengembangan Alat Destilator Bioetanol Model Refluk Bertingkat Dengan Bahan Baku Singkong," SIMETRIS, vol. 5, no. 2, pp. 4-5, 2014.

[8] J. . Holman, Heat Transfer. singapore: McGraw.Hill, 1986. 